\title{
The use of glucose measurements to improve screening for diabetes in clinical practice
}

\author{
ADAM R NICHOLLS, ${ }^{1,2}$ DANKMAR BÖHNING, ${ }^{3}$ RICHARD HOLT,1,2 PATRICK SHARP2
}

\begin{abstract}
Introduction: It is estimated that 4 million people will be living with diabetes in England by 2025. It is imperative that we can accurately identify people at risk of diabetes and target interventions to prevent its development.

Aim: To determine whether the addition of glucose measurements to the Leicester Risk Assessment Score (LRAS) improves the prediction of $\mathrm{HbA}_{1 \mathrm{c}} \geq 42 \mathrm{mmol} / \mathrm{mol}(6.0 \%)$ compared with a risk score alone, and reduces the number requiring additional tests to determine their glycaemic status.

Method: LRAS and $\mathrm{HbA}_{1 \mathrm{c}}$ were assessed in $\mathbf{4 8 4}$ participants (aged 40-80 years). 184 participants recruited directly from primary care underwent a fasting glucose measurement while 300 participants recruited through advertisement to the general public attended for a random capillary glucose.

Results: A LRAS of $\geq 17$ had a sensitivity of $79.6 \%$ and specificity of $60.1 \%$ to predict the $\mathrm{HbA}_{1 \mathrm{c}}$ value of $\geq 42 \mathrm{mmol} / \mathrm{mol}$ $(6.0 \%)$. The addition of a fasting glucose to the LRAS improved the explained variation in $\mathrm{HbA}_{1 \mathrm{c}}$ from $20.8 \%$ with a risk score alone to $46.7 \%$. In addition the number of people requiring further assessment of their glucose status was reduced from $43.8 \%$ to $33.2 \%$. The addition of a random capillary glucose to the LRAS did not significantly improve the model.

Conclusions: The addition of a fasting blood glucose, but not a random capillary glucose, to the LRAS improves the prediction of $\mathrm{HbA}_{1 \mathrm{c}} \geq 42 \mathrm{mmol} / \mathrm{mol}(6.0 \%)$ and reduced the number of people who would need further diagnostic testing for diabetes.

Br J Diabetes 2016;16:123-127
\end{abstract}

Key words: type 2 diabetes, screening, prevention, $\mathrm{HbA}_{1 \mathrm{c}}$

Human Development and Health Academic Unit, University of Southampton

University Hospital Southampton NHS Foundation Trust

Southampton Statistical Sciences Research Institute, University of Southampton

Address for correspondence: Dr Adam Nicholls The Institute for Developmental Sciences (MP887), Southampton General Hospital, Tremona Road, Southampton, SO16 6YD, UK. Tel: +44 (0)23 81204665

E-mail: a.nicholls3@nhs.net

http://dx.doi.org/10.15277/bjd.2016.090

\section{Introduction}

The past year has seen the launch of the National Diabetes Prevention Programme which aims to identify those at risk of diabetes early, and to undertake trials of preventative interventions. An efficient screening programme which will identify people at risk of diabetes who should be targeted for preventative intervention is needed. There are unresolved issues around the identification of those at future risk of diabetes, but one option recommended by the National Institute for Health and Care Excellence (NICE) is to use glycated haemoglobin $\left(\mathrm{HbA}_{1 \mathrm{C}}\right) .{ }^{1}$ This approach is controversial, but it would avoid the issue of poor repeatability and inconvenience of the oral glucose tolerance test which has dogged the area for many years. There is a growing body of evidence around the use of $\mathrm{HbA}_{1 \mathrm{c}}$ in diagnosis and screening for diabetes. ${ }^{2-5}$ The NICE guidance on diabetes risk identification and prevention and the Public Health England report on diabetes prevention recommend the use of an $\mathrm{HbA}_{1}$ c value of $42-47 \mathrm{mmol} / \mathrm{mol}(6.0-6.5 \%)$ to denote those at increased risk of future diabetes. $5,6 \mathrm{~A}$ recent health technology appraisal concluded it may also be the most cost-effective blood test. ${ }^{7}$

Despite the convenience of using $\mathrm{HbA}_{1 \mathrm{c}}$ as a screening tool, universal screening of the adult population by $\mathrm{HbA}_{1 \mathrm{c}}$ will be too expensive and will exceed capacity within the NHS, and so an inexpensive pre-screening test is needed. ${ }^{7}$ Currently, screening is via a number of risk stratification scores which make use of simple non-invasive clinical data. ${ }^{8-12}$ Nevertheless, despite prescreening by these methods, a significant proportion (up to $50 \%$ ) of the adult population would still need further blood testing. ${ }^{9}$ Any further simple testing which could screen out larger numbers may represent a significant financial saving to the NHS. In this project, we explore the most efficient method of predicting an $\mathrm{HbA}_{1 \mathrm{c}} \geq 42 \mathrm{mmol} / \mathrm{mol}$ (6.0\%) in order to minimise the numbers who need to proceed to further diabetes testing by $\mathrm{HbA}_{1 \mathrm{c}}$.

\section{Methods}

Participants were recruited if they were aged $40-80$ years and were not known to have diabetes. The results presented here were drawn from two separate study groups.

The first group was recruited directly from a GP list. The practice contacted registered patients who fulfilled the recruitment criteria listed above. With a single contact letter the positive response rate was 38\%. Participants attended the Wellcome Clinical Research Facility at Southampton General Hospital. Information which allowed calculation of the Leicester Risk Assessment Score (LRAS) was collected: age, gender, ethnicity, family 
Figure 1. Components of the Leicester Risk Assessment Score

\begin{tabular}{|l|l|l|}
\hline Parameter & & Score \\
\hline Age & $40-49$ & 0 \\
& $50-59$ & 5 \\
& $60-69$ & 9 \\
\hline Sex & $70-75$ & 13 \\
& Male & 0 \\
\hline Ethnicity & Female & 1 \\
\hline First degree family history & White & 0 \\
of type 2 DM & Other & 6 \\
\hline Waist circumference & Yo & 0 \\
& $<90$ & 5 \\
& $90-99$ & 0 \\
Body Mass Index & $100-109$ & 4 \\
& $\geq 110$ cm & 6 \\
& $<25$ & 9 \\
\hline Anti-hypertensive medication & $25-29$ & 0 \\
of high blood pressure & $30-34$ & 3 \\
\hline
\end{tabular}

history of diabetes, waist circumference, body mass index, and history of antihypertensive treatment. A copy of the score is shown in Figure 1. This group then underwent venous blood sampling for measurement of fasting blood glucose (FBG) by the Beckman Coulter Hexokinase method and $\mathrm{HbA}_{1 c}$ by Sebia capillary electrophoresis in the pathology department at University Hospital Southampton.

The second group was recruited by advertisement to the general public and by the same inclusion criteria as the first group. This group had the same demographic and anthropometric measurements collected to allow calculation of the LRAS. HbA $1 c$ and random capillary blood glucose (CBG; Abbott Freestyle meter) were then measured. In this cohort, haemoglobin $(\mathrm{Hb})$ was also measured to assess the relationship between $\mathrm{Hb}$ and $\mathrm{HbA}_{1 \mathrm{c}}$ in a general cross section of the adult population.

\section{Statistical analysis}

The results from both groups were initially pooled to validate the performance of the LRAS in predicting an $\mathrm{HbA}_{1 c}$ of $\geq 42 \mathrm{mmol} / \mathrm{mol}(6.0 \%)$. A sensitivity of $80 \%$ was taken as an acceptable benchmark in the context of diabetes screening, and the values closest to that target were assessed in terms of associated specificity and sensitivity. Subsequently, the impact of the FPG from the first group and the CBG from the second group were assessed in terms of change in numbers screening positive while maintaining a sensitivity as close as possible to $80 \%$.

Diagnostic accuracy was measured by sensitivity (the detection of those participants who truly had a $\left.\mathrm{HbA}{ }_{1 c} \geq 42 \mathrm{mmol} / \mathrm{mol}(6.0 \%)\right)$ and specificity (the detection of the participants with $\mathrm{HbA}_{1 \mathrm{c}}<42$ $\mathrm{mmol} / \mathrm{mol}(6.0 \%))$. Overall diagnostic accuracy was measured by the likelihood ratio positive (sensitivity divided by 1 minus specificity) and the Youden index (sensitivity + specificity - 100\%)..$^{13}$ Linear regression modelling $y=a+b 1 \times 1+b 2 \times 2$ was used to determine the relationship of $y=\mathrm{HbA}_{1}$ c to covariates $x 1=\mathrm{LRAS}$ and $\times 2=F B G$ (first group) or CBG (second group). The importance of the covari-
Table 1 Clinical characteristics of participants

\begin{tabular}{|c|c|c|}
\hline & $\begin{array}{l}\text { Registered } \\
\text { primary care } \\
\text { patients }\end{array}$ & $\begin{array}{l}\text { General } \\
\text { population }\end{array}$ \\
\hline Number (number female) & $184(102)$ & $300(218)$ \\
\hline Median age (y) (range) & $58.5(41-80)$ & $54.5(40-79)$ \\
\hline $\begin{array}{l}\text { Ethnic groups } \\
\text { White European } \\
\text { South Asian } \\
\text { African-Caribbean } \\
\text { Other }\end{array}$ & $\begin{array}{c}165 \\
11 \\
2 \\
5\end{array}$ & $\begin{array}{c}284 \\
8 \\
4 \\
4\end{array}$ \\
\hline $\begin{array}{l}\text { Body Mass Index }(\text { mean } \pm S D) \\
\mathrm{kg} / \mathrm{m}^{2}\end{array}$ & $28.2 \pm 5.1$ & $28.0 \pm 6.2$ \\
\hline $\begin{array}{l}\mathrm{HbA}_{1 \mathrm{c}} \mathrm{mmol} / \mathrm{mol}, \\
\text { mean } \pm \mathrm{SD}(\text { range) } \\
\mathrm{DCCT} \%, \text { mean } \pm \mathrm{SD} \text { (range) }\end{array}$ & $\begin{aligned} 39 & \pm 5(23-62) \\
5.7 \% & \pm 0.5(4.3-7.8)\end{aligned}$ & $\begin{array}{c}34 \pm 5(11-57) \\
5.3 \% \pm 0.4(3.2-7.4)\end{array}$ \\
\hline
\end{tabular}

ate $\times 2$ was determined with the increase of $\mathrm{R} 2$ when the covariate was added to the model. Here R2 stands for the percentage variance in $\mathrm{HbA}_{1 c}(\mathrm{y})$ explained by the model. The higher the increase, the more important is the covariate.

The area under the receiver operating curve (ROC) was used to compare models.

\section{Results}

\section{Study subjects}

A total of 184 individuals were studied in the practice based group and 300 in the general population group. The participant characteristics are shown in Table 1.

\section{Performance of LRAS}

In the pooled study group of 484 individuals, linear regression with $\mathrm{HbA}_{1 \mathrm{c}}$ as the dependent variable and LRAS as the explanatory variable returned an R2 value of $20.3 \%$. To examine the relationship in more detail, the sensitivity, specificity and numbers screening positive were calculated (Table 2). A LRAS value of $\geq 17$ was associated with a sensitivity closest to $80 \%$ and was therefore adopted as the benchmark in subsequent comparisons.

\section{Performance of FBG and LRAS}

In the practice based group, linear regression of $\mathrm{HbA}_{1 \mathrm{c}}$ as dependent variable against the LRAS as predictor returned an R2 of $20.8 \%$. The combination of the LRAS and FBG increased this value to $46.7 \%$. Table 3 shows that the diagnostic accuracy as measured by the Youden Index and likelihood ratio positive is highest for LRAS $\geq 17$ and FBG $\geq 5.3 \mathrm{mmol} / \mathrm{L}$. Combining the result of LRAS $\geq 17$ and $F B G \geq 5.3 \mathrm{mmol} / \mathrm{L}$, the sensitivity to predict an $\mathrm{HbA}_{1}$ c value of $\geq 42 \mathrm{mmol} / \mathrm{mol}(6 \%)$ was only marginally reduced at $76.2 \%$ but the numbers screening positive were reduced from $43.8 \%$ to $33.2 \%$ (Table 3 ). The area under the ROC curve was significantly increased from 0.76 to 0.85 by the addition of a FBG to the LRAS ( $p=0.0019)$ (Figure 2). 
Table 2 Predictive performance of the Leicester Risk Assessment Score (LRAS) alone in screening for $\mathrm{HbA} 1 \mathrm{c}$ of $\geq 42 \mathrm{mmol} / \mathrm{mol}(6.0 \%)$ in the combined groups

\begin{tabular}{lccccc}
\hline LRAS & Sensitivity (\%) & Specificity (\%) & \% to screen & Likelihood ratio & Youden Index (\%) \\
$\geq \mathbf{1 5}$ & 85.2 & 55.1 & 49.2 & 1.7 & 40.3 \\
$\geq \mathbf{1 6}$ & 83.3 & 57.7 & 46.7 & 2.0 & 41.0 \\
$\geq \mathbf{1 7}$ & 79.6 & 60.1 & 43.8 & 2.0 & 39.7 \\
$\geq \mathbf{1 8}$ & 77.8 & 65.2 & 39.5 & 2.2 & 43.0 \\
$\geq \mathbf{1 9}$ & 74.1 & 67.5 & 37.0 & 2.3 & 41.6
\end{tabular}

Table 3 Predictive performance of combined Leicester Risk Assessment Score (LRAS) at $\geq 17$ with a fasting blood glucose (FBG) in screening for $\mathrm{HbA}_{1 \mathrm{c}}$ of $\geq 42 \mathrm{mmol} / \mathrm{mol}(6.0 \%)$ in patients registered in primary care

\begin{tabular}{lccccc}
\hline & Sensitivity (\%) & Specificity (\%) & \% to screen & Likelihood ratio & Youden Index (\%) \\
LRAS $\geq \mathbf{1 7}$ and FBG $\mathbf{5 . 2} \mathbf{~ m m o l} / \mathbf{L}$ & 81.0 & 55.4 & 40.2 & 1.8 & 36.4 \\
LRAS $\geq \mathbf{1 7}$ and FBG $\mathbf{5 . 3} \mathbf{~ m m o l} / \mathbf{L}$ & 76.2 & 79.6 & 33.2 & 3.7 & 55.8 \\
LRAS $\geq \mathbf{1 7}$ and FBG $\mathbf{5 . 4} \mathbf{~ m m o l} / \mathbf{L}$ & 69 & 80.1 & 30.6 & 3.5 & 49.1
\end{tabular}

Figure 2. Receiver operating characteristics curve predicting $\mathrm{HbA}_{1 \mathrm{c}}>42 \mathrm{mmol} / \mathrm{mol}$ using Leicester Risk Assessment Score (LRAS), and LRAS + fasting blood glucose (FBG)

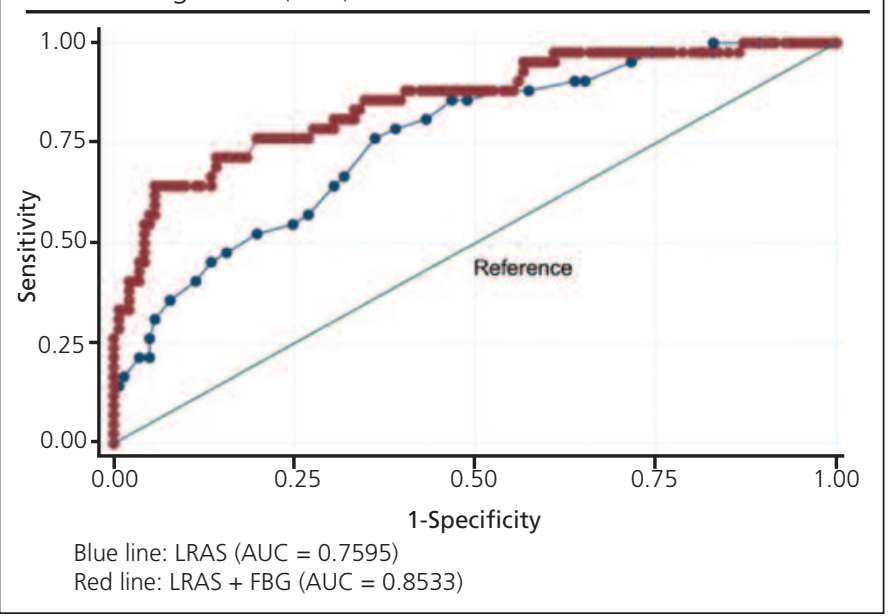

\section{Performance of random CBG and LRAS}

In the general population group, the utility of using a random finger prick CBG value to predict a $\mathrm{HbA}_{1 \mathrm{c}}$ value of $\geq 42 \mathrm{mmol} / \mathrm{mol}(6 \%)$ was explored. Again, linear regression of $\mathrm{HbA}_{1 \mathrm{c}}$ result against LRAS returned an R2 value of $16.0 \%$. Addition of the CBG as predictor variable increased this value to $19.0 \%$. There was a non-significant increase in the area under the ROC curve (Figure 3) from 0.75 to $0.80(p=0.2286)$, showing no significant benefit by adding a random CBG to the LRAS.

Simple correlation of the $\mathrm{HbA}_{1 \mathrm{c}}$ value against $\mathrm{Hb}$ demonstrated a weak positive correlation $(r=0.16, p=0.005)$. However, inclusion of the $\mathrm{Hb}$ value in the regression equation with LRAS as a predictor of $\mathrm{HbA}_{1 \mathrm{c}}$ did not significantly change the model statistics.
Figure 3. Receiver operating characteristics curve predicting $\mathrm{HbA}_{1 \mathrm{c}}>42 \mathrm{mmol} / \mathrm{mol}$ using Leicester Risk Assessment Score (LRAS) with and without capillary blood glucose (CBG)

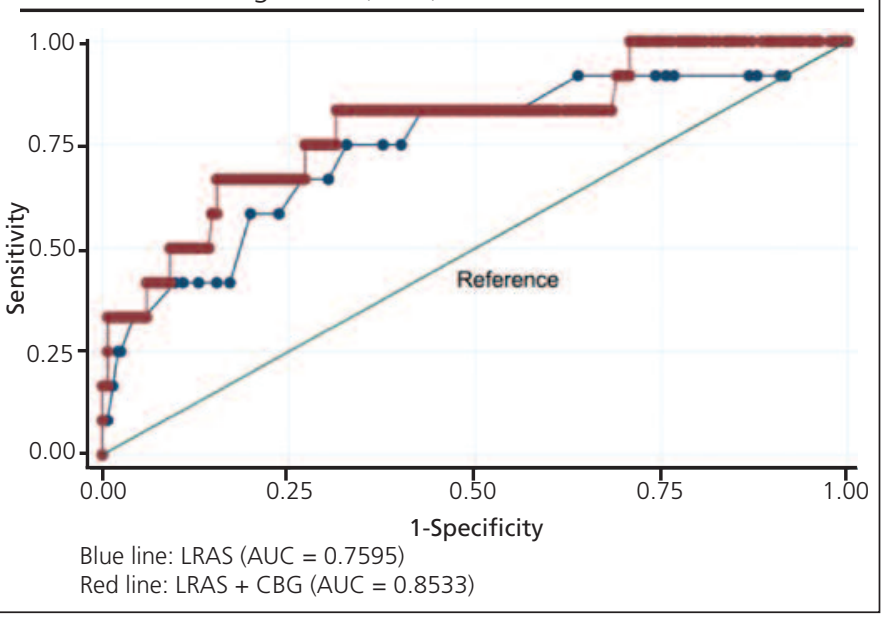

\section{Discussion}

The consensus in diabetes screening is that there is value in screening the adult population for diabetes although clear evidence for long term benefit is presently lacking. ${ }^{14}$ Although NICE published guidance on prevention of diabetes, it stopped short of advocating a universal screening programme. ${ }^{5}$ Nevertheless, the recent proposal from NHS England to fund diabetes prevention opens the topic for review once again as it will be important to detect those at risk for targeted preventative strategies. ${ }^{15}$

For the purposes of this study we have used the absolute value of $\mathrm{HbA}_{1 \mathrm{c}}$ recommended by NICE and NHS England as the marker of glucose dysregulation. Traditionally, diabetes or prediabetes have been defined by glucose measurements based on a substantial body of evidence. ${ }^{1,16}$ However, there is also consid- 
erable support for the use of $\mathrm{HbA}_{1 \mathrm{c}}$ as a predictor of both microvascular and macrovascular disease. ${ }^{17-19}$ Measurement of $\mathrm{HbA}_{1 \mathrm{c}}$ has practical advantages over the use of glucose measurements. It need not be taken on a fasting sample, is stable during transport to the laboratory and measurement is now subject to a recognised standard. For these reasons, we have opted to use $\mathrm{HbA}_{1 \mathrm{c}}$ for screening in this report. At a cut-off point of $42 \mathrm{mmol} / \mathrm{mol}(6.0 \%)$, the relative risk of vascular disease is approximately 1.5 and retinopathy becomes apparent. The EpicNorfolk trial demonstrates that $36 \%$ of cases of incident diabetes are detected in the $6 \%$ of the population with an $\mathrm{HbA}_{1 \mathrm{c}}$ in the range $42-47 \mathrm{mmol} / \mathrm{mol}(6.0-6.5 \%)$ over a 3-year period. ${ }^{3}$ It is also important to note that the screening uptake is likely to be significantly higher with the use of $\mathrm{HbA}_{1 \mathrm{c}}$ rather than alternative testing such as an oral glucose tolerance test. ${ }^{7}$

The accepted method for pre-screening for diabetes is by the use of simple risk scores. This is supported by a recent health technology appraisal as universal screening is likely to exceed capacity and not be cost effective unless the prevalence of diabetes in the population is particularly high. ${ }^{7}$ For the purposes of this work, we have used the LRAS as it is published and validated in the UK, returns a numerical score which can be handled statistically and is commonly in use, forming the basis of the diabetes risk score on the Diabetes UK website. We have validated the use of the LRAS to detect the target $\mathrm{HbA}_{1 c}$ value in our combined study population, finding a value of $\geq 17$ to be optimal with a sensitivity closest to the target value of $80 \%$. In the original work from Leicester, UK, a cut-off point of 16 was found to be the best fit to detect any glucose dysregulation. ${ }^{8}$ Their study population was considerably larger and ethnically more diverse, and these factors may account for the small difference. The optimal LRAS cut-off point of $>13$ quoted in the Public Health England report is markedly different from those reported here. The reasons for this relate to the fact that their data were taken from the Health Survey for England, and therefore included all individuals over the age of 16 years. ${ }^{6}$ Furthermore, data on family history of diabetes were not available as part of that survey and were set to null. As the purpose of that report was to compare different risk scores, the setting of family history to null for all scores did not affect the comparison between them. However, both of these factors skewed the distribution for the results of the LRAS markedly to the left. For the purposes of this study we have used the cut-off point of 17 as the reference. ${ }^{6}$

The use of the LRAS at a cut-off point of 17 will screen out approximately $57 \%$ of the population from further investigation. Nevertheless, the measurement of $\mathrm{HbA}_{1 \mathrm{c}}$ for $43 \%$ of the adult population at a unit cost to the NHS of approximately $f 4.04,20$ together with clinical and administrative staff time, would be expensive. We therefore examined whether any other measurements could reduce the numbers needed to screen. Unsurprisingly, measurement of a laboratory FBG performed well as a predictor of $\mathrm{HbA}_{1 \mathrm{c}}$ and, in combination with the LRAS, screened out a further $10 \%$ of the population from further testing. We found a FBG level of $5.3 \mathrm{mmol} / \mathrm{L}$ to be the best fit with a sensitivity closest to $80 \%$. This figure is lower than the figure

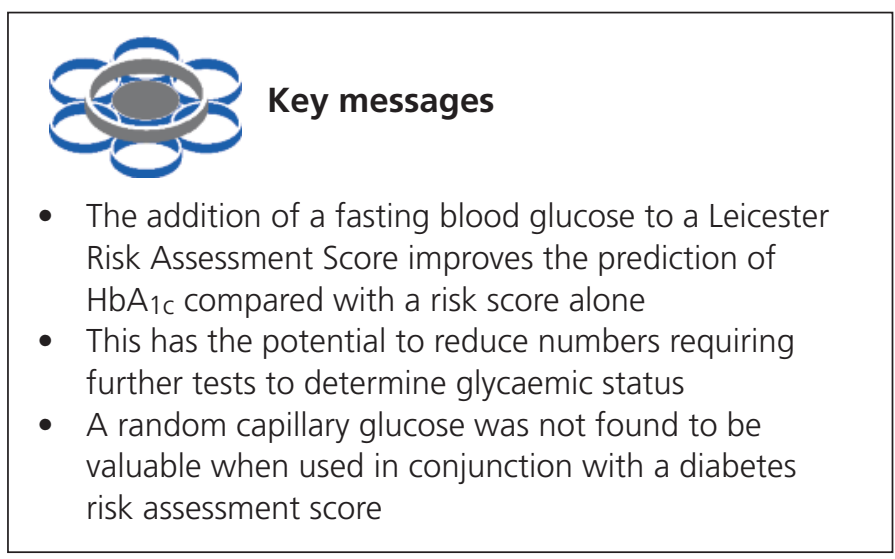

of $5.6 \mathrm{mmol} / \mathrm{L}$ derived in a study designed to detect impaired glucose tolerance using an oral glucose tolerance test. ${ }^{21}$ This discrepancy underscores the problems encountered when trying to find equivalence between the various categorical definitions of diabetes and glucose regulation. Despite these findings, use of FBG is not practical as a screening tool as it is less convenient for patients and requires a high volume of early morning appointments in primary care. However, it provides proof of concept that glucose measurements can screen out significant numbers from further testing. As a lower cost option, a random CBG was modelled. Unfortunately this did not improve the model in terms of screening out individuals from further testing. This would agree with the work of others who looked at this previously, albeit with a view to predict diabetes diagnosed by glucose testing. 22,23

In this study we have confirmed that there is a weak association between $\mathrm{HbA}_{1 \mathrm{c}}$ and $\mathrm{Hb}$. This has been a subject of discussion in the debate over the validity of $\mathrm{HbA}_{1 \mathrm{c}}$ measurement in the diagnosis of diabetes, particularly as it is known that various anaemias can affect the $\mathrm{HbA}_{1}$ c result. 24,25 In this study, the association was weak and was not found to be a significant factor in prediction of $\mathrm{HbA}_{1} \mathrm{c}$ when included with the various other factors included in diabetes risk scoring.

In conclusion, we have confirmed that current risk factor based screening for diabetes and prediabetes can be useful in screening out over $50 \%$ of the population from the need for further testing. At present, use of risk scoring using simple clinical data remains the gold standard. However, we have demonstrated that glucose measurements have the potential to screen out further significant numbers, but random glucose measurement has little value.

\section{Conflict of interest None. \\ Funding No external funding.}

\section{References}

1. Waugh NR, Shyangdan D, Taylor-Phillips S, Suri G, Hall B. Screening for type 2 diabetes: a short report for the National Screening Committee. Health technology assessment 2013;17:1-90. http://dx.doi.org/10.3310/hta17350

2. International Expert Committee. International Expert Committee report on the role of the A $1 \mathrm{C}$ assay in the diagnosis of diabetes. Diabetes Care 2009;32:1327-34. http://dx.doi.org/10.2337/dc09-9033 
3. Chamnan P, Simmons RK, Forouhi NG, et al. Incidence of type 2 diabetes using proposed $\mathrm{HbA} 1 \mathrm{c}$ diagnostic criteria in the european prospective investigation of cancer-norfolk cohort: implications for preventive strategies. Diabetes Care 2011;34:950-6. http://dx.doi.org/10.2337/dc09-2326

4. Preiss D, Khunti K, Sattar N. Combined cardiovascular and diabetes risk assessment in primary care. Diabet Med 2011;28:19-22. http://dx.doi.org/10.1111/j.1464-5491.2010.03157.x

5. National Institute for Health and Care Excellence (NICE). Preventing type 2 diabetes: risk identification and interventions for individuals at high risk. Public Health Guideline no 38. London 2012.

6. National Cardiovascular Intelligence Network. NHS Diabetes Prevention Programme (NHSDPP) Non-diabetic Hyperglycaemia. Public Health England, London, 2015.

7. Gillett M, Brennan A, Watson P, et al. The cost-effectiveness of testing strategies for type 2 diabetes: a modelling study. Health Technol Assess 2015;19:1-80. http://dx.doi.org/ 10.3310/hta19330

8. Gray LJ, Taub NA, Khunti K, et al. The Leicester Risk Assessment score for detecting undiagnosed Type 2 diabetes and impaired glucose regulation for use in a multiethnic UK setting. Diabet Med 2010;27:88795.http://dx.doi.org/10.1111/j.1464-5491.2010.03037.x

9. Gray LJ, Davies MJ, Hiles $\mathrm{S}$, et al. Detection of impaired glucose regulation and/or type 2 diabetes mellitus, using primary care electronic data, in a multiethnic UK community setting. Diabetologia 2012;55:959-66. http://dx.doi.org/10.1007/s00125-011-2432-x

10. Lindstrom J, Tuomilehto J. The diabetes risk score: a practical tool to predict type 2 diabetes risk. Diabetes Care 2003;26:725-31. http://dx.doi.org/10.2337/diacare.26.3.725

11. Collins GS, Altman DG. External validation of QDSCORE((R)) for predicting the 10-year risk of developing Type 2 diabetes. Diabet Med 2011; 28:599-607. http://dx. doi.org/10.1111/j.1464-5491.2011.03237.x

12. Gray LJ, Khunti K, Edwardson C, et al. Implementation of the automated Leicester Practice Risk Score in two diabetes prevention trials provides a high yield of people with abnormal glucose tolerance. Diabetologia 2012:55:3238-44. http://dx.doi.org/10.1007/s00125-012-2725-8

13. Böhning $D H H$, Patilea V. A limitation of the diagnostic-odds ratio in determining an optimal cut-off value for a continuous diagnostic test. Stat Methods Med Res 2011;20:541-50. http://dx.doi.org/10.1177/0962280210374532

14. Griffin SJ, Borch-Johnsen K, Davies MJ, et al. Effect of early intensive multifactorial therapy on 5-year cardiovascular outcomes in individuals with type 2 diabetes detected by screening (ADDITION-Europe): a clus- ter-randomised trial. Lancet 2011;378:156-67. http://dx.doi.org/10.1016/S0140-6736(11)60698-3

15. NHS England. NHS Diabetes Prevention Programme 2015. Available from: https://www.england.nhs.uk/ourwork/qual-clin-lead/action-for-diabetes/diabetes-prevention/.

16. The Emerging Risk Factors Collaboration. Diabetes mellitus, fasting blood glucose concentration, and risk of vascular disease: a collaborative metaanalysis of 102 prospective studies. Lancet 2010;375:2215-22. http://dx.doi.org/10.1016/S0140-6736(10)60484-9

17. Colagiuri S, Lee CMY, Wong TY, et al. Glycemic thresholds for diabetesspecific retinopathy: implications for diagnostic criteria for diabetes. Diabetes Care 2011;34:145-50. http://dx.doi.org/10.2337/dc10-1206

18. Khaw KT, Wareham N, Bingham S, Luben R, Welch A, Day N. Association of hemoglobin $\mathrm{A} 1 \mathrm{C}$ with cardiovascular disease and mortality in adults: the European prospective investigation into cancer in Norfolk. Ann Intern Med 2004;141:413-20. http://dx.doi.org/10.7326/0003-4819-141-6-200409210-00006

19. Muntner P, Wildman RP, Reynolds K, Desalvo KB, Chen J, Fonseca V. Relationship between $\mathrm{HbA} 1 \mathrm{c}$ level and peripheral arterial disease. Diabetes Care 2005;28:1981-7. http://dx.doi.org/10.2337/diacare.28.8.1981

20. Hyperglycaemia in Acute Coronary Syndromes Costing Statement: Implementing NICE guidelines. In: Excellence NIfHaC, editor. London 2011.

21. Hu Y, Liu W, Chen Y, et al. Combined use of fasting plasma glucose and glycated hemoglobin A1C in the screening of diabetes and impaired glucose tolerance. Acta Diabetol 2010;47:231-6. http://dx.doi.org/10.1007/s00592-009-0143-2

22. Engelgau MM, Thompson TJ, Smith PJ, et al. Screening for diabetes mellitus in adults. The utility of random capillary blood glucose measurements. Diabetes Care 1995:18:463-6. http://dx.doi.org/10.2337/diacare.18.4.463

23. Simmons D, Williams DR. Random blood glucose as a screening test for diabetes in a biethnic population. Diabetic Med 1994;11:830-5. http://dx.doi.org/10.1111/j.1464-5491.1994.tb00364.x

24. El-Agouza I, Abu Shahla A, Sirdah M. The effect of iron deficiency anaemia on the levels of haemoglobin subtypes: possible consequences for clinical diagnosis. Clin Lab Haematol 2002:24:285-9. http://dx.doi.org/10.1046/j.1365-2257.2002.00464.x

25. John WG. Use of HbA1C in the diagnosis of diabetes mellitus in the UK. The implementation of World Health Organization guidance 2011 Diabetic Med 2012;29:1350-7. 